Original Contribution

\title{
MANUAL HANDLING RISK ASSESSMENT AND MORBIDITY STRUCTURE AMONG WORKERS EMPLOYED IN METAL PRODUCING AND PROCESSING
}

\author{
P. Gidikova*, G. Sandeva \\ Section of Hygiene and Medical Ecology, Faculty of Medicine, Trakia University, Stara Zagora, \\ Bulgaria
}

\begin{abstract}
Regular manual handling at work still cannot be avoided despite current technological advancements. Manual handling of loads (MHL) is one of the most common causes of musculoskeletal disorders (MSDs). PURPOSE of the study was to evaluate the risk of manual handling in workers from an iron casting plant and a forging and pressing plant and to analyze morbidity for employees with high and moderate risk of MHL. METHOD used for risk assessment included the main characteristics of MHL determined by Directive 90/269/EEC. The structure of morbidity was analyzed based on the results from medical examinations and on data about temporary sick-leave. RESULTS from risk assessment showed high risk for 8 positions, moderate for 13 and acceptable risk for 12 positions engaged in production in an iron casting plant and forging and pressing plant. Analysis of morbidity among workers with high and moderate risk showed a significant percentage (25-30\%) of MSDs mainly of the spine. These diseases were also a major cause of temporary sick-leave. The rate of MSDs in workers with high or moderate risk from manual handling was higher compared with other workers employed in production in those plants. CONCLUSIONS: Preventive and corrective activities for MHL risk reduction need to be enforced.
\end{abstract}

Key words: manual handling, musculoskeletal disorders, iron casting, iron pressing.

\section{INTRODUCTION}

Regular manual handling at work includes lifting, putting down, carrying or moving, pushing or pulling of loads by one or more workers during the larger part of the work shift $(1,2)$. Despite current technological advancements manual handling occurs in almost all working environments (3). According to the Fourth European Working Conditions Survey carried out in the EU-27 in $2005,35 \%$ of all workers are exposed to the risk of carrying or moving heavy loads for at least a quarter of their working time (4). A recent Eurobarometer survey reports that workers consider ergonomic risks (repetitive movements or tiring or painful positions) to be one of the main occupational risks - $28 \%$, followed by lifting carrying or moving loads on a daily basis - $24 \%$ (5). Manual handling can result in fatigue, and lead to injuries of the back, neck, shoulders, arms or other body parts.

\footnotetext{
*Correspondence to: Pavlina Gidikova, Address: Department of Hygiene and Medical Ecology, Faculty of Medicine, 11 Armeyska Str, 6000 Stara Zagora, Bulgaria, Phone: +35942664329, E-mail: pgidikova@yahoo.com
}

Manual handling of loads may cause disorders due to gradual and cumulative deterioration of the musculoskeletal system through continuous lifting / handling activities. Damages of the musculoskeletal structures (muscles, tendons, ligaments, bones, joints, bursa and nerves) as a consequence of gradual and cumulative wear and tear through repetitive manual handling are called musculoskeletal disorders 'MSDs' (3). Manual handling of loads is one of the most common causes of musculoskeletal disorders in workers (6).

\section{PURPOSE}

The purpose of this study was to evaluate the risk of manual handling of loads (MHL) in workers from an iron casting plant and a forging and pressing plant and to analyze the structure of morbidity in employees with high and moderate risk of MHL.

\section{MATERIALS AND METHODS}

Risk from manual handling was evaluated for 24 positions in the iron casting plant and for 9 positions from the forging and pressing plant. All jobs investigated were directly involved in the production and the manual material handling was a significant part from their 
working tasks. The Method for MHL risk assessment was adapted by the authors from Leitfaden - Sicherheit und Gesundheitsschutz bei der manuellen Handhabung von Lasten (7, 8). The main characteristics of manual handling, determined by Directive 90/269/EEC were included in the risk assessment $(1,9,10)$ :

- repeatability and total duration of MHL in a working shift;

- weight of loads (iron castings, metal billets or other materials);

- load characteristics (too heavy or too large, unwieldy or difficult to grasp, unstable with sharp edges, high temperature or other health hazards);

- working posture (awkward, standing or walking a few steps, slight forward bending);

- working movements (turning, twisting, bending, stretching);

- distance to reach the load (distance from the body, height of lifting and lowering the load);

- working environment and working conditions (restrictions on movements from working space, clothes or personal protective equipment, instability of the floor, working surface, bad working conditions: temperature, humidity, ventilation, lighting).

The workers' capability for manual handling defined by adequate training, physical capacity, previous injuries and health condition was also taken into account in risk assessment.

The structure of morbidity was analyzed based on the results from medical examinations and on data about illness with day loss for three consecutive years. The rate of diseases registered was determined after grouping according to International Classification of Diseases 10th Revision (ICD-10). The structures of morbidity and temporary sickleave in workers with high and moderate MHL risk were compared with those in other workers directly involved in the production, but without significant risk from manual handling.

\section{RESULTS}

For both plants high risk from manual handling was found for 8 positions, moderate for 13 and acceptable risk for 12 positions (Table 1).

Therefore, $28 \%$ (32 males and 26 females) of workers employed in iron casting production were at high risk from MHL and 23\% (46 males) were at moderate risk. For the forging and pressing plant 4.3\% (6 males) of production workers were at high risk and $39 \%$ (47 males and 7 females) were at moderate risk from MHL.

The analysis of results from medical examination of workers with high and moderate risk (131 males and 33 females) showed a significant percentage of MSDs mainly of the spine - dorsalgia, spondylosis, osteochondrosis, intervertebral disc injuries and related damage and compression of nerve roots and plexuses. Diseases of musculoskeletal system along with related diseases of nervous system were $31 \%$ from all morbidity registered in workers with risk from manual handling (Figure 1). For comparison, the rate of these diseases was $17 \%$ in other workers involved in production without or with low MHL risk (123 males and 57 females).
WORKERS WITH MANUAL HANDLING RISK

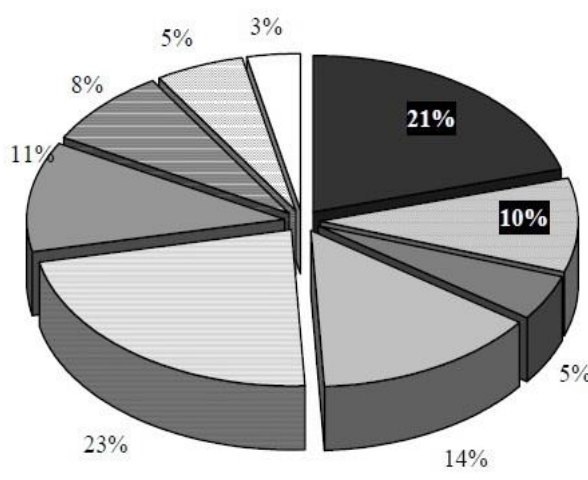

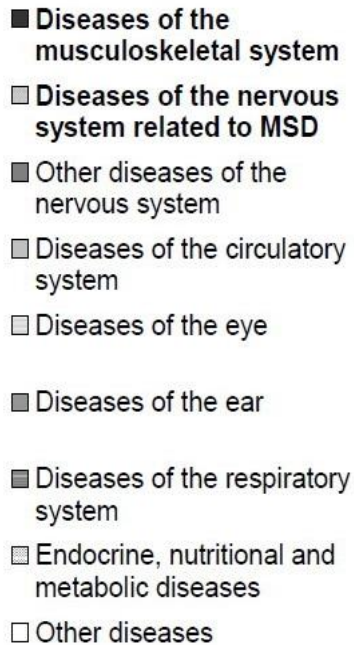

OTHER WORKERS IN PRODUCTION

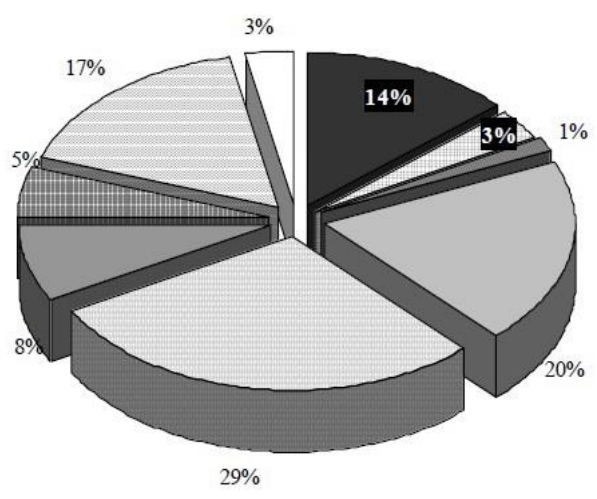

Figure 1. Rate of morbidity among workers with high and moderate risk from manual handling and other workers employed in metal production and processing 
Table 1. Positions and working operations with high and moderate risk from manual handling.

\begin{tabular}{|c|c|c|}
\hline Position & Sex & Working operation \\
\hline \multicolumn{3}{|c|}{ HIGH RISK - Iron casting plant } \\
\hline $\begin{array}{l}\text { casting cleaner } \\
\text { (manual handling) }\end{array}$ & M & $\begin{array}{l}\text { manual separation of castings with hammer and carrying } \\
\text { castings to pallet }\end{array}$ \\
\hline furnace mason & M & carrying and stacking of castings and different loads \\
\hline casting packer & $\mathrm{F}$ & carrying and stacking of castings in pallets \\
\hline $\begin{array}{l}\text { shot blasting machine } \\
\text { operator }\end{array}$ & M & manual loading of castings (over $20 \mathrm{~kg}$ ) in shot blasting machine \\
\hline $\begin{array}{l}\text { casting core maker } \\
\text { (handmade) }\end{array}$ & $\mathrm{F}$ & hand making of casting cores with weight $10-15 \mathrm{~kg}$ \\
\hline $\begin{array}{l}\text { emery worker } \\
\text { (stationary emery) }\end{array}$ & $\mathrm{F}$ & handling and cleaning of castings on stationary emery \\
\hline $\begin{array}{l}\text { emery worker } \\
\text { (big handheld grinder) }\end{array}$ & & $\begin{array}{l}\text { cleaning of heavy castings (over } 20 \mathrm{~kg} \text { ) with big handheld } \\
\text { grinder }\end{array}$ \\
\hline \multicolumn{3}{|c|}{ HIGH RISK - Forging and pressing plant } \\
\hline \multirow{2}{*}{$\begin{array}{l}\text { quality controller of metal } \\
\text { forgings }\end{array}$} & \multirow{2}{*}{ M } & grading and stacking of small $(<10 \mathrm{~kg})$ forgings \\
\hline & & grading and stacking of medium (10-20kg) forgings \\
\hline \multicolumn{3}{|c|}{ MODERATE RISK - Iron casting plant } \\
\hline molder (conveyor) & M & carrying full moulds to conveyor \\
\hline $\begin{array}{l}\text { emery worker } \\
\text { (small handheld grinder) }\end{array}$ & M & $\begin{array}{l}\text { cleaning of castings with small handheld grinder and loading } \\
\text { castings in pallets }\end{array}$ \\
\hline \multirow{3}{*}{ caster (conveyor) } & \multirow{3}{*}{ M } & pulling castings from shaking grate \\
\hline & & manual handling of metal casting forms \\
\hline & & manual weighing of casting forms \\
\hline $\begin{array}{l}\text { caster } \\
\text { (automatic molding line) }\end{array}$ & M & pulling castings from shaking grate \\
\hline $\begin{array}{l}\text { operator metal casting } \\
\text { (automatic molding line) }\end{array}$ & M & manual placing of casting cores \\
\hline $\begin{array}{l}\text { emery worker (blasting } \\
\text { grit) }\end{array}$ & M & cleaning of internal channels of castings \\
\hline \multicolumn{3}{|c|}{ MODERATE RISK - Forging and pressing plant } \\
\hline pressing machine operator & M F & working on pressing machine $1600 \mathrm{~kg}$ \\
\hline pressing machine operator & M & working on pressing machine $2500 \mathrm{~kg}$ \\
\hline $\begin{array}{l}\text { emery worker } \\
\text { (handheld grinder) }\end{array}$ & & $\begin{array}{l}\text { cleaning of forgings with handheld grinder and loading forgings } \\
\text { in pallets }\end{array}$ \\
\hline $\begin{array}{l}\text { emery worker } \\
\text { (stationary emery) }\end{array}$ & M & handling and cleaning of castings by stationary emery \\
\hline operator hardening & M & loading and unloading of forgings \\
\hline \multirow{2}{*}{ forging hammer operator } & \multirow{2}{*}{ M } & working by forging hammer - medium forgings \\
\hline & & working by forging hammer - big forgings \\
\hline \multirow{2}{*}{ calibration press operator } & \multirow{2}{*}{$\begin{array}{l}\mathrm{F} \\
\mathrm{M}\end{array}$} & calibration of medium forgings \\
\hline & & calibration of big forgings \\
\hline
\end{tabular}


Relatively high rate was estimated for diseases of the eye and diseases of the circulatory system among all workers included in examination, but a possible reason for these could be the age of workers (average 45 years) and not the working conditions.

The diseases of the musculoskeletal and nervous system were also a major cause of morbidity with day loss $-22 \%$ from the cases
GIDIKOVA P., et al. with temporary sick-leave in workers with high or moderate MHL risk and $20 \%$ for the other production workers (Figure 2). This trend was also observed in the analysis of the days lost $18 \%$ for MHL risk exposed workers and $17 \%$ for others (Figure 3). The average duration of a sick-leave for diseases of the musculoskeletal system was 7-10 days, and for those of the nervous system -5 days.

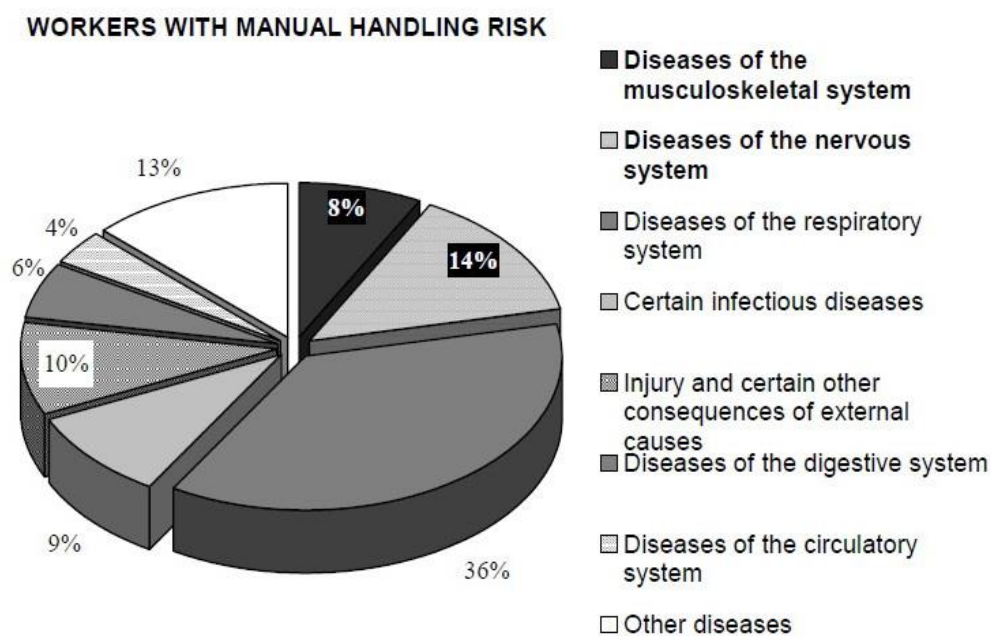

OTHER WORKERS IN PRODUCTION

Figure 2. Rate of cases with temporary sick-leave among workers with high and moderate risk from manual handling and other workers employed in metal production and processing

WORKERS WITH MANUAL HANDLING RISK

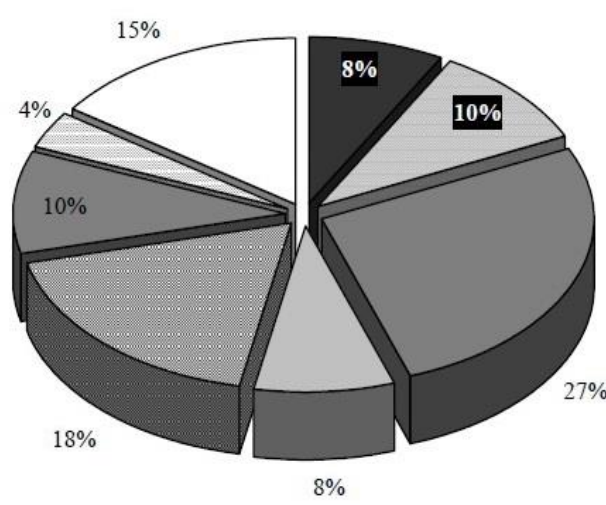

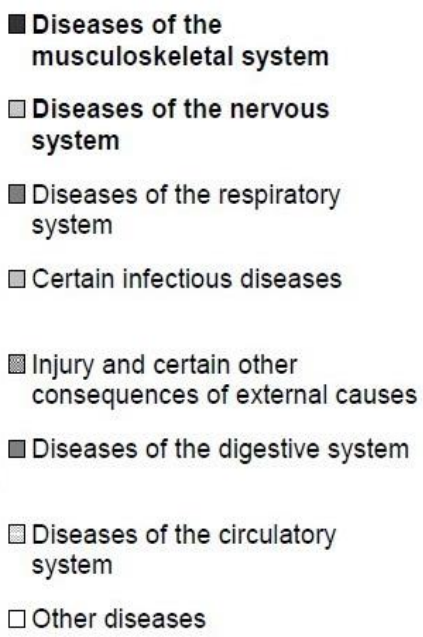

$\square$ Diseases of the

Diseases of the nervous system

Diseases of the respiratory

Injury and certain other consequences of external causes $\square$ Diseases of the digestive system

Diseases of the circulatory

$\square$ Other diseases
OTHER WORKERS IN PRODUCTION

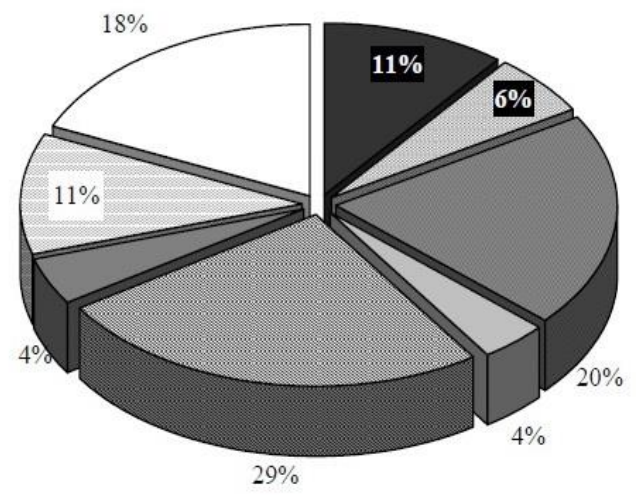

Figure 3. Rate of lost days with temporary sick-leave among workers with high and moderate risk from manual handling and other workers employed in metal production and processing

The rate of MSDs in workers with high or moderate risk from manual handling was higher compared with other workers employed in production in both plants.

\section{DISCUSSION}

A risk assessment has to be undertaken to determine the MHL hazards that workers are exposed to.

Once an assessment has taken place and the risks are identified, appropriate measures to 
prevent exposure can be facilitated (10, 11). The assessment and risk reduction steps use the ergonomic approach, where a range of relevant factors, including nature of the task, load characteristics, working environment and individual capability are considered (12). In our study we determined that $51 \%$ of all workers involved in production of iron casting and $43 \%$ of the employed in forging and pressing metal production were exposed to high or moderate risk from manual handling. These rates correspond to sectoral breakdown of rates of exposure to manual handling reported by the European Agency for Safety and Health at Work - $68 \%$ of workers in agriculture, $64 \%$ in construction, $48 \%$ in hotels and restaurants, followed by workers in the sectors of manufacturing and mining, wholesale and retail trade - close to $42 \%$, and transport and communications - 35\% (3). The comparison shows that rate of workers exposed to manual handling risk in metal production and processing was one of the highest in the manufacturing sector.

The high or moderate risk from manual handling determined for 21 positions came from different hazardous characteristics - too heavy loads, which were unwieldy or difficult to grasp, with sharp edges, necessity of gripping with protective gloves; high repeatability and long duration of MHL; awkward working posture; non-ergonomic design of the workplace and working environment.

The most common health problems that can arise from hazardous manual tasks are injuries or diseases of the musculoskeletal system known as MSDs. Musculoskeletal disorders may arise in whole or in part from performing manual tasks in the workplace, whether occurring suddenly or over a prolonged period of time $(3,6,13)$. In the present study the structure of morbidity was examined taking into account the musculoskeletal diseases and related diseases of nervous system that could be caused mainly by repetitive manual handling and not by manual handling accidents. The rate of these classes of diseases $(31 \%)$ is similar to other results reported. The European Agency for Safety and Health at Work notes that about a fourth of European workers suffer from back pain, which tops the list of all reported work-related disorders (3). The US Bureau of Labor Statistics reported that MSDs accounted for $30 \%$ of the nonfatal injuries and illnesses requiring days away from work in 2006 and 20\% of those in 2011 (11). Work-related musculoskeletal disorders (MSDs) account for over a third of all workplace injuries in United Kingdom (10). Manual material handling $(\mathrm{MMH})$ work contributes to a large percentage of the over half a million cases of musculoskeletal disorders reported annually in the United States (14).

Almost all of the MSDs registered in examined workers were mainly of the spine intervertebral disc injuries and hernias and related compression of nerve roots and plexuses, and also dorsalgia, spondylosis, osteochondrosis. Op De Beeck and Hermans found that about $25 \%$ of European workers consider that their work affects their health in the form of back pain, which tops the list of all reported work-related disorders (15). Workrelated low back pain and low back injuries are the most common kind of musculoskeletal disorders caused by manual handling. These work-related low back disorders are a significant and increasing problem in Europe (3). But this is a problem not only for European workers. In a study of morbidity pattern among iron and steel workers from an industry in Central India Biswas et al. observed that commonest morbidity in the workers $(33.25 \%)$ was lumbago, i.e. musculoskeletal pain (16). Study by Aghilinejad et al., (2012) showed that among Iranian steel workers, $46.3 \%$ in the past week and $61 \%$ in the last year claimed to have one of the following musculoskeletal disorders - of the spine, knee(s), and neck (17).

The higher rate of musculoskeletal diseases and related diseases of nervous system in workers exposed to high or moderate MHL risk compared with the other workers involved in metal production and processing confirms the significant contribution of hazardous manual handling for MSDs.

Musculoskeletal and nervous diseases were an essential part of cases with days lost from workers employed in iron casting plant and forging and pressing plant. The latest estimates from the British Labour Force Survey (LFS) show that the total number of MSD cases in 2013/14 was 526000 out of a total 1241000 for all work-related illnesses and the total number of working days lost due to MSDs was 8.3 million (18). An average of 15.9 days per case of MSDs was estimated from LFS. It is significantly higher than the estimated in our study average duration of a sick-leave for musculoskeletal diseases.

Work-related musculoskeletal disorders due to manual handling may have serious consequences to workers. They can result in 
GIDIKOVA P., et al.

protracted pain, disability, medical treatment, and financial stress for those afflicted $(3,14)$. The employers often prefer to pay for workrelated health damages, either directly or through workers' compensation insurance, and they must also cope with the loss of the full capacity of their workers. The current demographic changes in Europe will worsen the problem with workforce capacity. According to Eurostat population projections (Europop 2010), the working population aged between 55 and 64 in the EU-27 is expected to increase by about $16 \%$ between 2010 and 2030 (19). The aged workers are more vulnerable to hazardous manual handling and prone to MSDs.

Sound health and safety for workers is necessary for a sustainable working life and active and healthy ageing, especially in light of the ageing working population and the extension of working life. Successfully prolonging working careers depends strongly on appropriate adaptation of workplaces and work organisation (19).

\section{CONCLUSIONS}

A risk assessment is a careful examination of what in the work could cause harm to people. It can then be decided whether sufficient precautions have been taken, or whether it is necessary to do more to prevent harm. The challenge is to eliminate, or at least reduce, the potential for accidents, injury or ill health that arise from working activities and tasks.

Manual handling is still a significant risk for workers employed in metal production and processing. Preventive and corrective activities for risk reduction have to be enforced: increasing automation and mechanization, providing information and adequate training for workers, better fit between the demands of the work tasks and the capabilities of workers, appropriate organizational measures to reduce exposure, improvement of the working environment and working conditions, optimization of rest periods. The implementation of these measures would reduce the morbidity and temporary sick-leave among the exposed workers.

\section{ACKNOWLEDGMENTS}

The authors would like to thank the employers and employees of the plants for collaboration and support during the study.

\section{REFERENCES}

1. European Council, Council Directive 90/269/EEC of 29 May 1990 on the minimum health and safety requirements for the manual handling of loads where there is a risk particularly of back injury to workers. Official Journal, L 156, 9-13, June 26, 1990.

2. Ordinance № 16 of 31 May 1999 on the physiological norms and rules for Manual Handling of loads (Наредба № 16 от 31.05.1999 г. за физиологични норми и правила за ръчна работа с тежести). Bulgarian State Gazette, 54, June 15, 1999.

3. European Agency for Safety and Health at Work, Hazards and risks associated with manual handling in the workplace. E-facts, 14, 2007. Available at https://osha.europa.eu/en/tools-andpublications/publications/efacts/efact14/view (retrieved 19 June, 2015).

4. Parent-Thirion, A., Macías, E., Hurley, J. and Vermeylen, G., Fourth European Working Conditions Survey. European Foundation for the Improvement of Living and Working Conditions, Dublin, Ireland, 2007.

5. European Commission, Flash Eurobarometer 398 Working Conditions Report. European Union, April, 2014. Available at http://ec.europa.eu/public_opinion/flash/fl _398_en.pdf (retrieved 19 June, 2015).

6. Health and Safety Executive, Musculoskeletal Disorders (MSDs). Available at http://www.hse.gov.uk/msd/msds.htm (retrieved 19 June, 2015).

7. Steinberg, U. and Windberg H., Leitfaden Sicherheit und Gesundheitsschutz bei der manuellen Handhabung von Lasten. In: Bundesanstalt fur Arbeitsmedizin: Schriftenreihe der Bundesanstalt fur Arbeitsmedizin, Berlin, Germany, 1994.

8. Министерство на труда и социалната политика, Рьководство за ръчна работа с тежести. София, България, 2003.

9. Tesh, K.M., Lancaster, R.G., Hanson, M.A., Ritchie, P.J., Donnan, P.T. and Graveling, R.A., Evaluation of the Manual Handling Operations Regulations 1992 and Guidance. Institute of Occupational Medicine for the Health and Safety Executive, Contract Research Report 152, Edinburg, Scotland, 1997.

10. Health and Safety Executive, Manual Handling at Work: A brief guide. INDG143(rev3), UK, 2012. Available at http://www.hse.gov.uk/pubns/indg143.pdf (retrieved 19 June, 2015).

11. Examinetics, Professional resources, Manual Handling. Avalable at 
http://www.examinetics.com/professionalresources/manual-handling/ (retrieved 19 June, 2015).

12. Graveling, R.A., Melrose, A.S. and Hanson, M.A., The principles of good manual handling: Achieving a consensus. Research Report 097, Institute of Occupational Medicine for the Health and Safety Executive, 2003.

13. Government of Western Australia, Commission for occupational safety and health. Code of practice, Manual Tasks, Australia, 2010.

14. Cal/OSHA Consultation Service, Research and Education Unit, Division of Occupational Safety and Health, Ergonomic Guidelines for Manual Material Handling. California Department of Industrial Relations, DHHS (NIOSH), OH, USA, 2007.

15. Op De Beeck, R. and Hermans, V., European Agency for Safety and Health at Work Research on work-related low back disorders. Office for Official Publications of the European Communities, Luxembourg, 2000.
16. Biswas, M.J., Koparkar, A.R., Joshi, M.P., Hajare, S.T. and Kasturwar, N.B., A study of morbidity pattern among iron and steel workers from an industry in central India. Indian J Occup Environ Med, 18(3):122128, 2014.

17. Aghilinejad, M., Choobineh, A.R., Sadeghi, Z., Nouri, M.K. and Bahrami Ahmadi A., Prevalence of musculoskeletal disorders among Iranian steel workers. Iran Red Crescent Med J, 14:198-203, 2012.

18. Health and safety statistics 2013/14, Annual Report for Great Britain, Musculoskeletal Disorders (MSDs) in Great Britain. Avalable at www.hse.gov.uk/statistics/causdis/musculo skeletal/index.htm

19. European Commission, Communication from the Commission to the European Parliament, the Council, the European Economic and Social Committee and the Committee of the region on an EU Strategic Framework on Health and Safety at Work 2014-2020. COM, 332 final, Brussels, Belgium, 2014. 